\title{
Studi Pengaruh Penambahan Kerang Hijau (Perna Viridis) sebagai Material Akustik pada Kemampuan Absorbsi Bunyi
}

\author{
Susilo Indrawati* \\ Jurusan Fisika, Fakultas Matematika dan Ilmu Pengetahuan Alam, \\ Institut Teknologi Sepuluh Nopember (ITS), Kampus ITS Sukolilo, Surabaya 60111
}

Intisari

\begin{abstract}
Kerang Hijau (Perna viridis) atau dikenal sebagai green mussels, memiliki sebaran yang luas hampir diseluruh lapisan dunia. Namun potensi limbah berupa cangkang kerang saat ini belum banyak dimanfaatkan. Berdasarkan data ekspor hasil perikanan Indonesia pada tahun 2003 dan 2004, untuk komoditas kerang dihasilkan sekitar 2.752 ton. Kegiatan pada unit pengolahan kerang hijau menghasilkan limbah padat yang cukup tinggi sehingga diperlukan upaya pemanfaatan cangkang kerang hijau dan mengurangi dampak negatif terhadap kesehatan manusia dan lingkungan. Mengingat dalam cangkang kerang memiliki banyak kalsium, dalam penelitian ini akan dilakukan studi awal pengaruh pemberian kerang hijau sebagai material akustik terhadap kemampuan dalam mengabsorbsi bunyi. Metode yang dilakukan adalah dengan menggunakan tabung Impedansi. Adapun bahan yang digunakan adalah semen putih, gypsum, agent foam dan bubuk kerang. Berdasar hasil pengukuran didapat perbandingan prosentasi material kulit kerang:semen putih:gypsum 4:0:2 (kerang 270 gr, tanpa semen putih, gypsum 135 gr) memiliki perubahan nilai koefisien absorbsi yang paling besar jika dibandingkan dengan perbandingan bahan yang lain.
\end{abstract}

\begin{abstract}
Green mussel (Perna viridis) is known as Green Shell, which has wide distribution in nearly all layers of the world. However, the potential of green leather shells have not been optimally used . Based on data from Indonesian exports of fishery products in 2003 and 2004, It's commodities produced approximately 2,752 tonnes. The result of Activity on unit processing the green mussel is the solid cesspit very high. So, there are needed effort to use it and reduce negative impacts on human health and the environment. Remember that the shells have a lot of calcium, so in this study will be conducted early studies about the effect of green mussels for ability an accoustic material to absorb sound. The method is using the impedance tube. The materials used are white cement, gypsum, foam agent and powder leather shells. The result from the measurement of the percentage ratio green leather shell: white cement: gypsum 4: 0: 2 (270 gr green leather shell, no white cement, gypsum 135 gr) has changes of value the greatest of absorption coefficient.
\end{abstract}

KATA KUNCI: green mussels, absorption coefficient, impedance tube

\section{PENDAHULUAN}

Indonesia merupakan negara yang mengikuti perkembangan ilmu dan teknologi. Inovasi baru terus dilahirkan dengan menggunakan material-material recycle. Salah satu bidang yang diperlukan untuk menambah estetika material akustik adalah inovasi-inovasi baru yang diketahui bahwa kebanyakan menggunakan mineral wool. Tentu saja material ini masih sulit dijangkau oleh masyarakat karena harganya yang relatif mahal.

Sebelumnya telah dilakukan penelitian tentang kualitas akustik panel dinding berbahan baku jerami yang telah dilakukan oleh Mediastika [1]. Panel jerami sebagai material akustik mampu mengolah bahan limbah menjadi panel yang

\footnotetext{
*E-MAIL: susilo_i@physics.its.ac.id
}

memiliki kekuatan struktural yang mencukupi dan kualitas akustik yang memadai. Namun penelitian ini memerlukan bahan tambahan yang sekiranya diperlukan untuk menjaga keawetan panel tersebut. Armando [2] meneliti tentang pemanfaatan limbah kulit kerang simping menjadi elemen estetika bangunan, yang hanya memandang dari sisi dari estetika bangunan belum di bahas mengenai pemanfaatan dalam material akustik.

Berdasarkan permasalahan di atas maka dilakukan studi pengaruh pemberian kerang hijau (perna viridis) sebagai material akustik terhadap kemampuan mengabsorbsi bunyi. Material yang digunakan sebanyak 5 macam yang merupakan gabungan dari kulit kerang, semen putih, gypsum dan agent foam dengan komposisi perbandingan bahan yaitu $0: 4: 2,1: 3: 2,2: 2: 2,3: 1: 2$ dan 4:0:2 . Bahan-bahan tersebut nantinya akan di ukur lebih lanjut dengan menggunakan tabung impedansi. Pengukuran dengan metode ini nantinya akan di peroleh perbandingan material akustik mana 


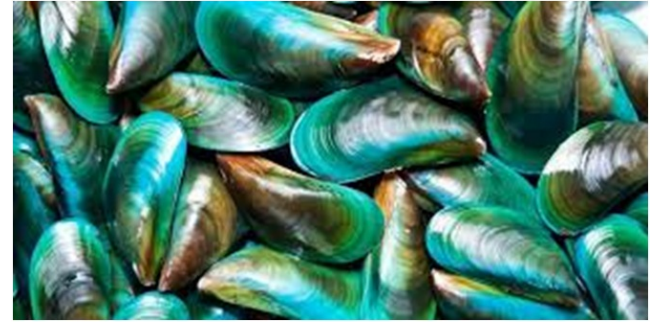

Gambar 1: Kerang hijau.

yang memiliki kemampuan paling besar dalam mengabsorbsi bunyi.

\section{Diskripsi kerang hijau}

Limbah kulitkerang hijau adalah salah satu material yang biasanya digunakan sebagai bahan kerajian yang dilakukan oleh sekelompok pengrajin di daerah pantai kenjeran, Surabaya. Kerang hijau (Perna viridis) atau biasanya dikenal dengan green mussels (Gambar 1) adalah binatang lunak (moluska) yang hidup di laut, bercangkang dua dan berwarna hijau.
Filum : Moluska
Kelas : Bivalvia
Ordo : Mytiloida
Famili : Mytilidae
Genus : Perna
Spesies : Perna viridis

Di daerah pinggir pantai Kenjeran kecamatan Sukolilo Surabaya banyak terdapat jenis kerang hijau ini yang masih memiliki nilai jual yang rendah serta pemanfaatan yang telah dilakukan sangatlah sedikit yang memberikan kontribusi terhadap suatu bangunan secara langsung. Biasanya warga sekitar memanfaatkan kulit kerang sebagai kerajinan tangan atau seni dekoratif, juga sebagai campuran makanan ternak guna memenuhi kadar kalsium [3]. Kandungan terbesar kulit kerang berupa kalsium karbonat, magnesium karbonat, kalsium fosfat dan sebagian kecil materi anorganik lain. Bahanbahan ini sering disebut dengan filter pada produksi cat, kertas, adhesif, kosmetik, semen adhesif dan lain-lain. [4].

\section{Klasifikasi material akustik}

Bahan-bahan material akustik ada beberapa yang dapat diklasifikasikan sebagai absorber secara khusus yaitu:

1. Mineral wool: mineral wool terbuat dari material pasir, batu basal, dan kaca daur ulang yang dilelehkan pada suhu tinggi

2. Foam(busa): Foam dapat memiliki struktur sel yang terbuka ataupun tertutup. Dengan struktur sel yang berbuka poros saling berhubungan san memiliki hasil absorbsi yang signifikan. Sedangkan untuk struktur sel tertutup sebaliknya.
3. Material daur ulang: Material ini menggunakan material-material yang dapat didaur ulang.

4. Gorden (tirai): gorden atau tirai merupakan material yang biasa digunkan sebagai penyerap berporus. Semakin dalam lipatan akan semakin menghasilkan absorpsi yang baik.

5. Karpet: karpet merupakan absorber berporus, yang biasanya memiliki proporsi absorbsi yang luas pada frekuensi tinggi di dalam ruang.

6. Aerogels: material ini merupakan zat padat yang memiliki porosiotas yang tinggi. Terbuat dari gel yang dicairkan kemudian berubah menjadi gas.

7. Karbon aktif: material ini mulai diminati dalam bidang akustik untuk meningkatkan kemampuan matrial akustik. Salahsatunya pembuat loadspeaker sudah menggunkan karbon aktif untuk meningkatkan performansi frekuensi rendah pada loadspeaker [5].

\section{Kriteria material akustik}

Bahan lembut, berpori dan kain serta juga manuasia, menyerap sebagian besar gelombang bunyi yang menumbuk mereka, dengan kata lain mereka adalah penyerap bunyi. Jumlah panas yang dihasilkan pada perubahan energi inni adalah sangat kecil, sedang kecepatan perambatan gelombang bunyi tidak dipengaruhi oleh penyerapan. Sebenarnya semua bahan bangunan menyerap bunyi sampai batas tertentu, tetapi pengendalian akustik bangunan yang baik membutuhkan penggunaan bahan-bahan dengan tingkat penyerapan bunyi yang tinggi. Untuk membuat suatu insulator harus memenuhi persyaratan sebagai berikut:

- Berat, material berat mampu meredam getaran yang menimpanya berkat beratnya sendiri.

- Keutuhan material, keutuhan material bergantung pada kerapatan bahan dan keseragaman material sehingga akan memiliki tingkat insulasi yang tetap dan stabil.

- Elastisitas, elastisitas akan mengurangi timbulnya resonansi. Namun kurang cocok dipakai sebagai konstruksi bangunan yang kuat.

- Prinsip isolasi, sangat bermanfaat untuk memperoleh tingkat insulasi yang tinggi.

\section{METODOLOGI PENELITIAN}

Peralatan yang digunakan dalam metode penelitian ini adalah menggunakan metode tabung impedansi seperti yang di tunjukkan dalam Gambar 2. Dalam penelitian ini juga digunakan software YMEC (Yoshimasa Electronic) yaitu software yang mampu mencatat dan menyimpan data sekaligus yang diterima oleh mikrophon. 
TABEL I: Komposisi campuran.

\begin{tabular}{cccc}
\hline \hline Nama & \multicolumn{2}{c}{ P e r b a n i i g a n } & k o m p o s i s i \\
Sampel & kulit kerang hijau & semen putih & gypsum \\
\hline Bahan 1 & 0 & 4 & 2 \\
Bahan 2 & 1 & 3 & 2 \\
Bahan 3 & 2 & 2 & 2 \\
Bahan 4 & 3 & 1 & 2 \\
Bahan 5 & 4 & 0 & 2 \\
\hline \hline
\end{tabular}

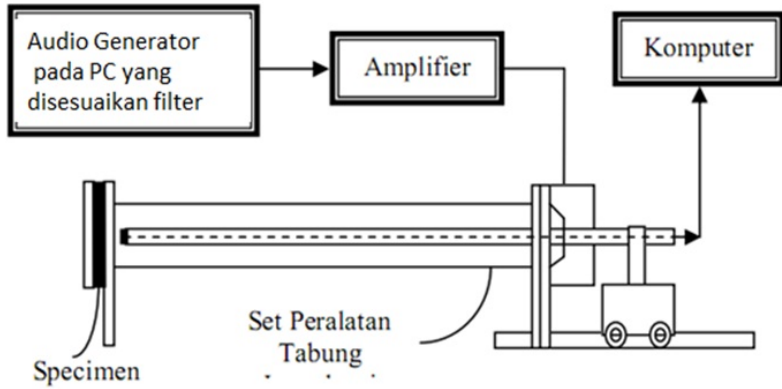

Gambar 2: Skema rangkaian untuk mengukur koefisien absorbsi.

\section{Pencampuran perekat dan pencetakan}

Bahan perekat seperti silica fume $6 \%$ dan specta foam $1 / 20$ dari bahan perekat dimasukkan ke dalam ember. Lalu bahan ini dicampur menggunakan mixer/blender hingga berbusa. Selanjutnya hasil campuran tersebut ditambahkan dengan sampel limbah kulit kerang dalam komposisi yang ditentukan, yaitu terdiri dari bahan-bahan yang berturut dengan perbandingan komposisi kulit kerang hijau : semen putih : gypsum seperti ditunjukkan Tabel I.

\section{Metode ukur dengan menggunakan tabung impedansi}

Tabung impedansi memiliki banyak versi dari bentuk silinder atau ukuran material sampel yang akan diuji. Pengukuran akan dilakukan dengan range frekuensi band oktaf. Untuk mengukur koefisien absorbs $(\alpha)$, maka perangkat keras yang telah disebutkan maka dirangkai seperti Gambar 2.

Metode tabung impedansi merupakan salah satu cara untuk mengukur absorpsi bahan pada gelombang bunyi. Penggunaan metode ini berdasarkan dua standart, yaitu ISO 105342:1998 dan ASTM E1050-98, prinsip dasar metode tabung impedansi adalah refleksi, absorpsi dan transmisi gelombang bunyi oleh permukaan bahan. Sumber bunyi yang berasal dari speaker nantinya akan dibangkitkan oleh amplifier yang kemudian bunyi akan diteruskan ke sample (specimen) dan data akan ditangkap oleh mikropon. Data yang ditangkap oleh mikropon merupakan data tingkat tekanan bunyi (SPL) refleksi dari sample. Adapun data yang diperoleh adalah data SPL maksimum dan SPL minumum yang nantinya akan diperoleh nilai selisihnya $(\Delta \mathrm{SPL})$ seperti yang ditunjukkan pada persamaan:
TABEL II: Background noise.

\begin{tabular}{cc}
\hline $\begin{array}{c}\text { Frekuensi } \\
(\mathrm{Hz})\end{array}$ & $\begin{array}{c}\text { Tingkat bising } \\
\text { sekitar }(\mathrm{dB})\end{array}$ \\
\hline 125 & $18,0-26,2$ \\
250 & $23,4-29,5$ \\
500 & $29,4-32,0$ \\
1000 & $27,4-29,2$ \\
2000 & $23,6-26,2$ \\
4000 & $24,0-26,7$ \\
\hline
\end{tabular}

TABEL III: Hasil pengukuran dengan menggunakan tabung impedansi.

\begin{tabular}{ccccccccccc}
\hline \hline Frek & \multicolumn{1}{c}{ T i n g k a t } & t e k a n a n & \multicolumn{2}{c}{ b u n y i } \\
$(\mathrm{Hz})$ & \multicolumn{1}{c}{ Bahan 1 } & \multicolumn{1}{c}{ Bahan 2 } & \multicolumn{2}{c}{ Bahan 3 } & \multicolumn{3}{c}{ Bahan 4 } & \multicolumn{2}{c}{ Bahan 5 } \\
& $\max$ & $\min$ & $\max$ & $\min$ & $\max$ & $\min$ & $\max$ & $\min$ & $\max$ & $\min$ \\
\hline 125 & 135,9 & 96,7 & 137,1 & 94,5 & 137,6 & 98,2 & 137,6 & 95,1 & 137 & 97 \\
97 & 132,7 & 86,1 & 133,5 & 90,8 & 133,6 & 89,3 & 133,5 & 94,6 & 133 & 95 \\
95 & 128,2 & 82,8 & 127,2 & 87,3 & 129,4 & 89,1 & 129,1 & 86 & 127 & 88 \\
88 & 99,6 & 53,8 & 99,5 & 53,9 & 102,8 & 61,4 & 100,5 & 64,3 & 101 & 65 \\
65 & 94 & 47 & 93 & 55,3 & 95,4 & 59,3 & 92,9 & 53,1 & 94 & 51 \\
51 & 99 & 65,2 & 93,4 & 56,6 & 93,8 & 58,5 & 95,8 & 55,9 & 93 & 61 \\
\hline \hline
\end{tabular}

$$
\alpha=1-\left(\frac{\log ^{-1}\left(\frac{\Delta S P L}{20}-1\right)}{\log ^{-1}\left(\frac{\Delta S P L}{20}+1\right)}\right)^{2}
$$

dengan $\alpha=$ koefisien absorpsi normal bahan, $\Delta \mathrm{SPL}=$ selisih tingkat tekanan bunyi maximum dan tingkat tekanan bunyi minimum.

\section{HASIL DAN PEMBAHASAN}

Pengukuran koefisien absorbsi bunyi seperti pada Pers. 1 diperlukan besarnya $\Delta \mathrm{SPL}$, sehingga perlu dilakukan pengukuran besarnya tingkat bising sekitar (background noise). Hasil pengukuran tingkat bising sekitar ditampilkan dalam Tabel II.

Setelah dilakukan pengukuran background noise yaitu dengan mengukur besarnya didapatkan data seperti ditunjukkan Tabel III. Berdasarkan data yang telah diolah diperoleh besarnya koefisien absorbsi seperti ditunjukkan pada Gambar 3.

Berdasar hasil koefisien yang diperoleh dengan menggunakan tabung impedansi dapat dilihat bahwa dari urutan 15 menyatakan bahwa bahan 1 (komposisi perbandingan kulit kerang, semen putih, gypsum $=0: 4: 2$ ) komposisi belum dicampurkan dengan bubuk kerang hijau kemudian dilanjutkan dengan bahan 2 (komposisi perbandingan kulit kerang, semen putih, gypsum $=1: 3: 2$ ) penambahan bubuk kerang hijau masih belum kelihatan hanya pada frekuensi $500 \mathrm{~Hz}$ meningkat sebesar 0,02 , kemudian setelah dilanjutkan dengan pengujian bahan 3, bahan 4 dan bahan 5 penambahan bubuk kerang cukup terlihat jelas hampir disemua frekuensi ada peningkatan sebesar 0,01, dari studi disini dapat kita lihat bahwa penambahan bubuk kerang hijau dapat mengabsorbsi bunyi. 


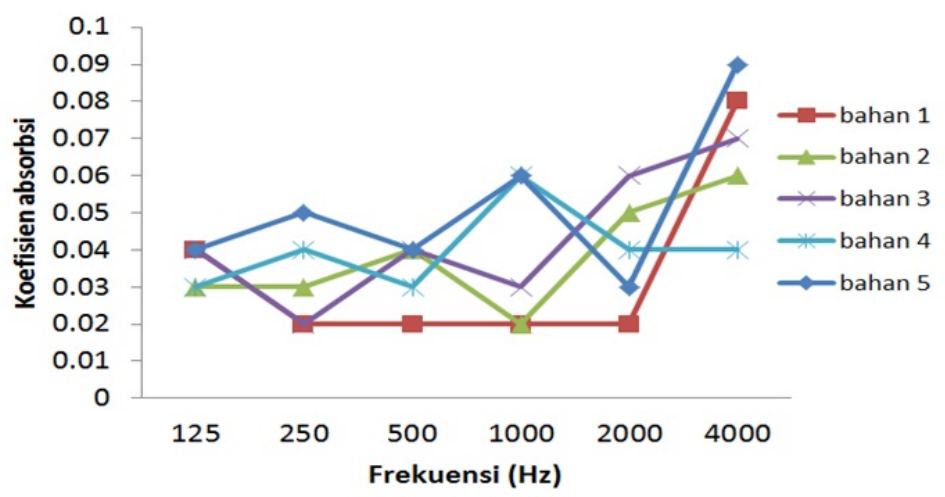

Gambar 3: Skema rangkaian untuk mengukur koefisien absorbsi.

\section{SIMPULAN}

Berdasarkan hasil pengukuran dengan metode tabung impedansi bahwa penambahan bubuk kerang hijau memiliki kemampuan untuk mengabsorbsi bunyi, Mulai tampak ada perubahan pada bahan 3, Sedangkan yang paling bagus yaitu pada bahan 5 dengan komposisi (komposisi perbandingan kulit kerang, semen putih, gypsum $=4: 0: 2$ )
[1] C. Mediastika, Akustika Bangunan - prinsip dan penerapannya di indonesia (Erlangga, Jakarta, 2005).

[2] A. Armando, dkk., Pemanfaatan limbah kulit kerang simping menjadi elemen estetika bangunan, Universitas Brawijaya, Malang, 2013.

[3] M. Nadjib, Berkala Penelitian Hayati 13, 153-156 (2008).
[4] M.C. Douglas, Chemical and process technology encyclopedia (McGraw-Hill Book, Company, USA, 1974).

[5] D.A. Russel, Absorption Coefficient and Impedance (Science and Mathematics Departement, Kettering University, Flint, MI, 48504). 